\title{
Experimental evidence of gold nanoparticles in sulfur-bearing hydrothermal ore fluids
}

\author{
Weinua LiU ${ }^{1}$, MiaO Chen ${ }^{1}$, Yi YANG ${ }^{1}$, YUAN Mei ${ }^{1}$, \\ BARBARA ETSCHMANN ${ }^{2}$, JOËL BRUGGER ${ }^{2}$, BERNT \\ JOHANNESSEN ${ }^{3}$ \\ ${ }^{1}$ CSIRO Mineral Resources, Clayton, Vic, 3168, Australia, \\ email: weihua.liu@csiro.au \\ ${ }^{2}$ School of Earth, Atmosphere and Environment, Monash \\ University, Clayton, Vic, 3800, Australia \\ ${ }^{3}$ Australian Synchrotron, Clayton, Vic, 3168, Australia
}

Most gold deposits formed from hydrothermal fluids in which gold is considered to be transported as aqueous complexes, such as hydrosulfide and chloride complexes. With the advance of new microanalytically tools to image and measure structural properties at nanoscales, increasing evidences show that gold nanoparticles (colloidal gold) may play an important role in the enrichment of gold in ore fluids, reviving the century-old theory of colloidal gold transport mechanism.

We have used Synchrotron X-ray Absorption Near-edge Structure (XANES) to investigate the stability of gold nanoparticles in sulfur-bearing and citrate-bearing solutions up to $225{ }^{\circ} \mathrm{C}$, and up to $350{ }^{\circ} \mathrm{C}$ with visual check of colour change (Liu et al., 2019). The citrate-based gold nanoparticles solutions, with or without colloidal silica in the solution, are only stable up to $225^{\circ} \mathrm{C}$. In contrast, the gold nanoparticles in $\mathrm{Na}_{2} \mathrm{~S}$ solutions are not stable upon heating to $150^{\circ} \mathrm{C}$, but stable up to $300^{\circ} \mathrm{C}$ when $0.5-1.5 \mathrm{wt} \%$ of colloidal silica is present in the solution. The gold nanoparticles started to aggregate and deposit from the solution with the aggregation and growth of silica particles at $350{ }^{\circ} \mathrm{C}$. The concentrations of gold as nanoparticles in the solutions are up to $0.5 \mathrm{mmol}(\sim 95$ ppm), more than three orders of magnitude higher than gold solubility as aqueous complexes under the same condition calculated based on available thermodynamic data. These results provide the first evidence that high concentrations of gold nanoparticles are stable in sulfur-bearing fluids at elevated temperatures $\left(\sim 300^{\circ} \mathrm{C}\right)$. The result implies that the formation of gold nanoparticles (colloids) is an effective way to concentrate gold in hydrothermal sulfur-bearing fluids to form high grade gold ores.

\section{References:}

Liu, W., Chen, M., Yang, Y., Mei, Y., Etschmann, B., Brugger, J. and Johannessen, B. (2019) Colloidal gold in sulphur and citrate-bearing hydrothermal fluids: An experimental study. Ore Geology Reviews 114, 103142. 